\title{
Patrick de Smet: Why change a winning team?
}

Nanda Uitslager

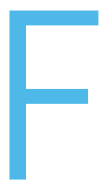

orty years living with haemophilia on two different continents has left Patrick de Smet with a unique perspective on his condition. He has experienced haemophilia the hard way but has no hard feelings. While he accepts that haemophilia care has advanced tremendously in recent years, he is happy with the treatments he knows, and with his decision that "with me the haemophilia stops."

Today, Patrick de Smet is well known as the (head) coordinator of the Belgian Haemophilia Society (Hemofilievereniging / Association de l'Hémophilie). He spends his time campaigning to raise awareness of the condition he has lived with for over four decades, explaining what it is like to live with haemophilia, how it changes over time, and why it is something to be managed rather than to be afraid of.

\section{GROWING UP}

Patrick spent the first twelve years of his life in Kinshasa in Zaire, Africa, now the Democratic Republic of the Congo, where his father worked for the Belgian government. He was born in 1977, the youngest of seven children. Two of his four brothers had haemophilia, while one of his two sisters carried the gene.

His parents discovered the hard way that Patrick's oldest brother had a bleeding disorder. Although he had tell-tale bruises as a young child, these were never examined in depth .

NANDA UITSLAGER

Advanced Nurse Practitioner, Department of

Haematology, Utrecht Medical Center, The Netherlands

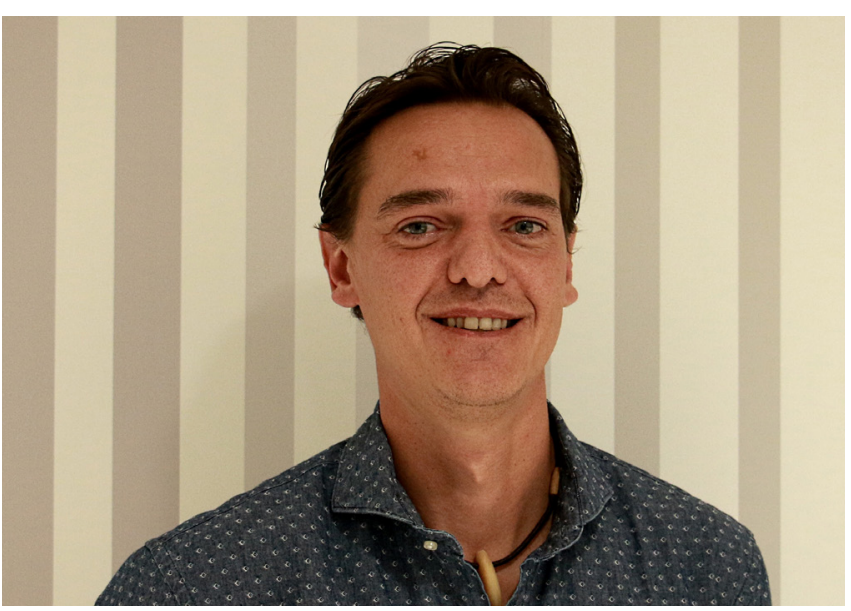

Having spent his childhood in Kinshasa, Zaire (now the Democratic Republic of Congo) before returning to Belgium in the late 1980s, Patrick de Smet has experienced two very different settings for haemophilia care. Starting prophylaxis in the 1990s enabled him to embark on a career in nursing. He now chairs the Belgian Haemophilia Society

"When my oldest brother was about three years old, they [Patrick's parents and his siblings] flew from Belgium back to Kinshasa. Due to the landing in Athens he fell against the seat in front of him and his teeth pierced the skin. He started to bleed from the wounds in his mouth and they were asked to leave the plane."

The diagnosis of severe haemophilia A was made in a hospital in Athens, where Patrick's brother received cryoprecipitate to stop the bleeding. It was then that his mother realised she was a carrier.

"I heard stories about my mother, back in Kinshasa, giving him her blood from one bed to the other. That was the first treatment." 
From then on, in Kinshasa, with limited access to hospitals and no specialist doctors, everything was a bit hands-on - Patrick says it is a miracle that his brother is still alive. But there was treatment - on demand, of course - and Patrick recalls that the family got its clotting factors via the Belgian embassy, initially in the form of cryoprecipitate, and later factor VIII.

"Every month there was a shipment to the Belgian Embassy that was always the same amount of units. In the '70s and '80s those were big boxes with bottles of 250 or $500 \mathrm{ml}$, which needed to be frozen. We had three or four big freezers in a row packed to the brim with the boxes. There were also boxes with IV drip systems."

Patrick says that both his parents were able to prepare and administer the cryoprecipitate.

"In our L-shaped living there was a loop in one corner and on that loop the bottles were attached. All three of us sat in a row next to one another receiving treatment, which could take one to two hours per bottle. The others played around us. I guess they felt like they came second, that haemophilia always came first."

But play was the order of the day. Patrick says his parents placed no restrictions on the boys' activities.

"We were free to do the same as the others - so we played football, walked a lot, we did everything. There was no difference between the boys with and without haemophilia. On the one hand I am happy that my parents raised us like that - we did saw and experienced a lot."

But he acknowledges that it took its toll on the boys' joints:

"We also suffered a lot. We had a bleed every week."

And of course, in Kinshasa, there were no haemophilia doctors.

"Every other year we went to Belgium for about two weeks, because my dad needed to get documents signed. That was the only time that we went to a haematologist."
At the age of 12 Patrick moved to Ostend (Oostende) in the Dutch speaking part of Belgium.

"I couldn't speak any Dutch or Flemish, because at home we spoke French. I kind of understood the Dutch, but could not speak it at all. Within a year I spoke Dutch."

The landscape was not the only change he experienced: although still treated on demand (which continued until the '90s, when he started prophylaxis) he switched to a different clotting factor. He developed an inhibitor, which took 18 months to eradicate with immune tolerance induction (ITI).

"Those 18 months were difficult. After the switch I had a major bleed in my lower back that compressed the nerves to my legs, so I was paralysed in both my legs. This was when we discovered that I had an inhibitor."

Patrick was treated with FEIBA and stayed in hospital for a long time. After the bleeding reduced and he returned home, he gradually regained the feeling in his legs and his mobility.

"But my leg muscles were very weak, so [I had] rehabilitation physiotherapy, which provoked a bleed in my knee - the one that is still bothering me. The knee joint was forced into an angle of 90 degrees without being able to flex. It took about 18 to 24 months before I was able to stretch my leg completely again. They had developed a routine to plaster my knee every two weeks to put pressure on the joint. They pushed it down and plastered it quickly, which was extremely painful during the first few days. In the end that saved the movement of my knee."

The treatment provoked knee bleeds so he was given FEIBA before each session, although bleeds sometimes still occurred.

"If the pain was too much due to pressure, the plaster was cut open and replaced. Sometimes I had an open cast with bandages. It took a long while before the right way to do this procedure was found, but in the end it worked."

\section{A CARING CAREER}

In Belgium some haemophilia treaters were relatively 
late in catching on to prophylaxis - but in 1996, the introduction of a prophylactic regimen enabled major changes in Patrick's life.

\section{"The main and most important change was not having the weekly bleeds any more. After a few months I thought, 'I have a completely different and new life.' I started to do things that I couldn't before. I started to work as a bartender, and during the weekends sometimes at a discotheque. My father had died, and I wanted to help my mother and family financially. But it was because of the prophylaxis that all of a sudden I could do these things. I had a wonderful time being a student. For my mother this period was financially difficult: five out of six children still living at home were studying at the time, which was very expensive."}

He also moved out of the family home in Ostend to live in Hasselt with his eldest sister, with whom he had always been very close. Both decided they would train to become nurses;

\section{"Working with people always appealed to me."}

Sadly, Patrick's sister was plagued by ill health. She worked as a home care nurse and struggled for some time with pain in her shoulders. Although she continued to work through the pain, eventually she was unable to drive her car and a scan revealed that she was suffering from bone cancer, with metastases throughout her body. No treatment was possible. Patrick was able to care for her, but she declined rapidly and died within eight months of being diagnosed.

After graduating, Patrick worked in the operating room, but his haemophilia began to impose limitations:

\footnotetext{
"My elbows, my ankles and knee became a problem, because I had to stand (still) for a long time. If I could walk, stand, walk and so on it was not a problem - but the constant standing and the lifting of the patients was. After two years I had to decide to leave. That was very hard because I really liked the work."
}

Initially he was offered a job in A\&E, but he declined as he felt it would not be too different from working in the operating room. He worked for six months at an orthodontist's practice while deciding what he wanted to do, before starting to work as a self-employed nurse caring for patients in their own homes. He took on only those patients he knew he could handle, which allowed him to set his own hours and pace, and specialised in stoma and wound care, diabetes, and patients returning home after surgery, at the end stages of cancer or with the onset of dementia.

As a home care nurse he also went into the homes of people with haemophilia to administer factor, and to educate parents and boys in infusion:

\section{"Because I was used to doing self-infusions, it was easy to explain to others and to show how you can do it."}

Patrick's strategy in teaching others was to let people practice on him, as much as they wanted, after first injecting himself so he was well covered.

\begin{abstract}
"It was a bonus that I could explain from my own experience what it can be to live with haemophilia, how it changes over time. Because there are still parents who are so afraid that they restrict their child out of fear of bleeds. Some believe it is life-threatening to dive into water, because that contact with water, After the switch I had a major bleed in my lower back that compressed the nerves to my legs, so I was paralysed in both my legs. This was when we discovered that I had an inhibitor."
\end{abstract}

He says many patients and parents experience a major change in their lives once they learn to selfinfuse, especially those families where the child has a portacath.

\begin{abstract}
"They were depending on normal home care to give the injections or went to the hospital, so they were housebound and unable to take holidays. For many, the most common reaction is 'What a freedom - we are able to pack our bags and go!' Today there are still families in Belgium that depend on others to inject their child. Some parents are just too afraid to do it themselves. If you are independent it lowers the burden of haemophilia."
\end{abstract}

\section{MARRIAGE AND CHILDREN}

It was while working as a home care nurse that Patrick met and married his wife. Based on earlier experiences, he was initially reluctant to disclose his haemophilia: 
"I have some injections scars but wear long sleeves. She did not see those initially."

But within two months of meeting her, Patrick had told her about his haemophilia. To his relief, her reaction was "So what?" It wasn't a big deal to her; she simply wanted to know more about it.

Based on his own experiences, Patrick was always certain that he did not want children.

"I would not have wished to burden my daughters with the problem of whether or not to have children. Do I want to pass this misery on into the future? I am one of the last generations that received on-demand treatment. The weekly bleeds with the pain, the fact that you were not able to move freely for two or three days, or sometimes a few weeks because of a bleed. That you cry day and night because of the severe pain."

Patrick made the personal choice "Haemophilia stops with me."

When they married, Patrick's wife understood and accepted his opinion. But when the opportunity of embryo selection was offered they did not hesitate;

"We have twin boys now."

Although he does not resent his mother for passing haemophilia on to him, Patrick says she always felt guilty for passing it on:

"...and not just when we decided to have boys only. We told her over and over again: no Mum, you shouldn't feel guilty, no one of us blames you. But she still blames herself. Although I am doing fine as is my eldest brother - although he has two hip and two knee replacements - she still lives with my handicapped brother, she lives with him every day, the confrontation."

With all the newer treatments now coming through, would he still decide for boys only?

"Yes, that would still be the same. Perhaps with the subcutaneous treatment it will be a bit better, but ten years ago they also said that it wasn't so bad any more to have a child with haemophilia.
"My children help me with the injections, they change the syringe. They even want to learn to inject. They have no needle phobia whatsoever. As they are seven, I will probably let them try within a few months. In Belgium is it not uncommon to train more people to inject the person with haemophilia, even children. I have used the same vein for 30 years now."

\section{IT'S TOUGH ON THE CHILDREN}

Although he was able to continue home care nursing for 15 years, Patrick's own haemophilia progressed. Over the last two to three years, it became increasingly difficult due to frequent knee bleeds and inflammation. During this period, he had to use a wheelchair at home. The boys were around four years old and, inevitably, wanted to play football or ride their bikes with their Daddy.
"You cannot explain to a four-year-old why Daddy just cannot do those things. It was hard to look after them on my own - I could not move properly with two boys doing what four-year- olds do. Sometimes I had to ignore myself and my pain to intervene."

Now they are seven, it is easier to explain and his knee is much better.

\begin{abstract}
"I am receiving corticosteroid injections. My knee is almost 'normal', I can ride a bike again and walk for miles, with some sore muscles afterwards. Running is just about 30/40 metres, before I need to stop because of pain. I am able to play with them much more. Finally, I can do the father/son activities that I missed out on for so long."
\end{abstract}

Because it was such a dominant part of his life, Patrick says he begged his haemophilia team to give him a new knee to end the pain. They argued that although the cartilage was gone the meniscus was partly all right, so there should be some movement. Eventually he became angry and insisted they do something as it was not fair to his children. The complaints resulted in consultations with doctors and rheumatologists, and many tests.

\footnotetext{
"One of them thought that a special kind of corticosteroid injection might help. Within ten days after the first injection the problem was solved. But I had walked around with this knee
} 
pain for two years. I had received an injection once before, but after a few months the effect was gone. Then two years with pain until the rheumatologists said they would try another kind of corticosteroid - and that did the trick."

Now, each time he feels the onset of pain or his knee swells, Patrick calls the haemophilia team and within two days gets the injection.

"They finally know that when I call it is time to handle it. The period between the injections stays a solid nine to eleven months and seems to be getting longer instead of shorter. As long as I have a part of my meniscus it will be like this. Whenever the meniscus is gone, another treatment is needed."

\section{TIME FOR A CHANGE}

As his knee joint worsened, Patrick found that working as a home care nurse became harder. Initially he used crutches to help him go and care for his patients.

\section{"Staying at home was not an option: as a haemophiliac I couldn't get health insurance if I did that. So I had to carry on, despite the pain, until I reached the point at which I had to quit my job."}

Fortuitously, around this time, the chair of the Belgian haemophilia patients' association retired, leaving a full-time vacancy. Patrick was the ideal candidate: not only had he coordinated his own business for 15 years, he also had enormous experience in haemophilia and knew most of the doctors and nurses within the Belgian haemophilia treatment centres.

"Physically this is the best job for me. It is not a physically demanding profession and I can decide which hours to work, and spread them over the day and week."

Life at home is also so much better:

"During my time as a home care nurse, I saw my first patient around six in the morning and was at home around nine or ten o'clock at night. Now I wake the boys up, take care of them, bring them to school and go to the office. In the evening I collect them from school. It has brought stability within the family."
Today, Patrick and his family continue to live in the countryside near Hasselt, where they have a very large fenced garden and a dog, who is able to run free.

"It is a small village, very remote, and surrounded by orchards. That was a choice for us to relax again, as well as the fact that we needed a bungalow. Stairs could become too big a hurdle for me."

Patrick is doing well and his haemophilia seems to be well controlled.

\section{"In the past 12 months I have had no spontaneous bleeds, so my haemophilia is currently very well managed, with injections three times a week."}

Although he has been offered an extended half-life factor, he is reluctant because he still believes the inhibitor he developed at age 12 was the result of a product switch.

"I am doing fine, and my veins are fine, so it is no burden to inject three times a week. And if I should fail, my wife can inject as well. Why change a winning team?"

\section{ACKNOWLEDGEMENTS}

Writing assistance was provided by Mike Holland, Haemnet.

The authors have advised no interests that might be perceived as posing a conflict or bias.

Informed consent has been obtained from the individual reported in this article.

HOW TO CITE THIS ARTICLE:

Uitslager N. Patrick de Smet: Why change a winning team?

J Haem Pract 2019; 6(1:suppl): S24-S28. https://dol.

org/10.17225/jhp00134. 